\title{
La casa y hacienda de un señor mexica: Un estudio analítico de la "Información de doña Isabel de Moctezuma"
}

\author{
Anastasya Kalyuta \\ Museo Ruso de Etnografía. Ministerio de Cultura. Rusia
}

El ensayo se dedica al análisis de los datos contenidos en la "Información de doña Isabel de Moctezuma", una serie de documentos que constituyen un testimonio detallado del litigio iniciado en 1546 por el conquistador Juan Cano de Saavedra en nombre de su esposa Tecuichpoctzin, bautizada como doña Isabel, hija de Motecuhzoma Xocoyotzin, el ultimo gobernante prehispánico de los mexicas. La meta del litigio consistió en la restitución de las tierras, edificios y objetos de valor declarados patrimonio de doña Isabel, que ella debía heredar de sus padres y abuelos, miembros del linaje gobernante de Tenochtitlan. La riqueza de datos históricos que nos presenta esta fuente la hace indispensable para el estudio, por un lado, de la tenencia de tierra entre la nobleza mexica prehispánica y, por el otro, de sus alianzas matrimoniales y de las estrategias desarrolladas por sus descendientes para combatir las realidades del periodo colonial.

PALABRAS ClAVES: tenencia de tierra, alianzas matrimoniales, herencia.

The essay is dedicated to analysis of the "Información de doña Isabel de Moctezuma", set of documents now belonging to the General Archive of Indies in Seville (Spain). This source is the detailed record of litigation initiated in 1546 by the conquistador Juan Cano de Saavedra on behalf of his wife, Tecuichpochtzin, the daughter of the last Prehispanic Mexica ruler Motecuhzoma Xocoyotzin who after the baptism was called doña Isabel de Moctezuma. The objective of litigation was the restitution of vast land holdings, buildings and objects of value, claimed to be doña Isabel "patrimony" (patrimonio) that is the property which she was to inherit from her parents and grandparents, members of the royal dynasty of Tenochtitlan, outlost during the Spanish conquest. The richness of the historical data contained in "Información de doña Isabel de Moctezuma" makes it invaluable source for study of such important topics as the land tenure and matrimonial alliances of the Prehispanic Mexica nobility and subsequent response of their descendants to the challenge of the Colonial period.

KEYwordS: Prehispanic Land Tenure. Marriage Practices. Postconquest Situation.

\section{Introducción}

No es casual que el título de este ensayo aluda de forma tan evidente al artículo "La casa y hacienda de un señor tlahuica" escrito en 1972 por el 
doctor Pedro Carrasco Pizana, investigador destacado sobre la sociedad nahuatl; en su artículo eran analizados los censos indígenas del actual Estado de Morelos y además se exponían unos testimonios hasta entonces desconocidos. ${ }^{1}$ El ensayo se basa en el estudio anterior de la "Información de doña Isabel de Moctezuma", una colección de documentos que actualmente se encuentran en el Archivo General de Indias en Sevilla, realizado en noviembre de 2006. Sus objetivos principales son: 1) plantear una nueva interpretación de los datos contenidos en estos expedientes; 2) reconstruir sobre la base de estos datos las formas de propiedades entre la nobleza mexica prehispánica y las correspondientes practicas de control y transferencia de los bienes dentro del linaje gobernante de Mexico Tenochtitlan.

La "Información" constituye un testimonio detallado del litigio iniciado en 1546 por el conquistador Juan Cano de Saavedra en nombre de su esposa, la hija del huey tlahtoani Motecuhzoma Xocoyotzin (Moctezuma II) el último señor mexica prehispánico, llamada tras la Conquista doña Isabel de Moctezuma. El fin del litigio no era otro que el de recuperar tierras, casas y objetos de valor que, según la fuente en cuestión, formaban el patrimonio que ella debía heredar de sus padres y abuelos, gobernantes de México Tenochtitlan. ${ }^{2}$ El original de la "Información" se perdió y actualmente disponemos de dos copias, ambas utilizadas en nuestro trabajo, junto con la versión paleográfica de la investigadora del INAH maestra Emma Pérez Rocha, que ella publicó en su libro "Privilegios en lucha: La Información de doña Isabel de Moctezuma". ${ }^{3}$ La primera copia se hizo en 1560 a petición de Juan Cano y ahora se encuentra en el AGI, Real Patronato, 181, R. 8. La segunda se hizo más tarde, en 1566, a petición de Juan de Andrade, hijo mayor de doña Isabel, de su matrimonio anterior con Pedro Gallego de Andrade y en la actualidad se localiza en el AGI, Patronato Real, 245, R. 3. Ambas copias incluyen: 1) cédula del príncipe (futuro rey Felipe II ), en la que se ordena a los jueces de la Real Audiencia de México que inicien una investigación sobre las tierras de Motecuhzoma y de su esposa Tecalco, la hija del tlahtoani (gobernante) Ahuitzotl; 2) carta-petición de Juan Cano dirigida al emperador Carlos V en nombre de doña Isabel de Moctezuma, en la que se describen todos los méritos de Motecuhzoma Xocoyotzin y "muchos bienes, rayzes, pueblos e casas y

1 Carrasco, Pedro: "La casa y hacienda de un señor tlalhuica", en Estudios de Cultura Nahuatl, vol. 10, México, 1972, págs. 222-252.

2 AGI, Patronato, 245, R. 3, fs. 5v-16v.

3 Pérez Rocha, Emma: Privilegios en lucha: La Información de doña Isabel de Moctezuma, INAH, México, 1998, págs. 16-18. 
rentas de gran valor" que tenían él y su esposa principal; 3) petición de Juan Cano al presidente de la Real Audiencia, en la que aquel solicita interrogar a los testigos seleccionados; 4) probanza que consiste en el interrogatorio (listado de 39 preguntas) y respuestas de testigos; 5) dictamen final de la Real Audiencia realizado en 1556. Ambos llevan asimismo firmas de dos escribanos públicos llamados Antonio de Turcios y Sancho López de Agurto confirmando su validez. ${ }^{5}$ Sin embargo, la copia de 1560 contiene 210 folios y presenta un total de 29 testigos en el proceso, mientras que la de 1566 comprende 125 folios y tiene declaraciones sólo de 11 testigos. ${ }^{6}$ En ambas es posible apreciar numerosos errores en cuanto a la transcripción de nombres propios y topónimos en nahuatl, omisiones de páginas íntegras, así como introducción en las respuestas de testigos indígenas de conceptos del derecho castellano por medio de la terminología respectiva, que pueden ser atribuidos tanto a los escribanos que sacaron las copias, como a la manipulación deliberada de datos conforme a la legislación castellana por parte de Juan Cano y Juan de Andrade Moctezuma.

A pesar de contener muchos testimonios de valor excepcional para el estudio de problemas tan importantes como la tenencia de tierra entre la nobleza mexica prehispánica, las alianzas matrimoniales y las estrategias de la nobleza de origen prehispánico para combatir las realidades del periodo colonial, la "Información de doña Isabel de Moctezuma" no recibió la atención debida por parte de los investigadores. El único estudio detallado de nuestra fuente fue el realizado por la maestra Pérez Rocha, que encontró estos expedientes en el AGI, en colaboración con el doctor Pedro Carrasco Pizana. Sus resultados fueron publicados en el libro que ya mencionamos arriba, que incluye el texto editado y revisado de ambas copias junto con el análisis del origen y del contenido de la fuente y con los índices toponímicos y onomásticos. Sin embargo, Pérez-Rocha y Pedro Carrasco subrayaban el carácter preliminar de su análisis que tenía como fin: "el hacer del conocimiento del lector la importancia del documento que aquí se presenta y de motivarlo a continuar su estudio".?

4 Ibidem, págs. 19, 49-51, 53-62, 271.

5 Ibidem, pág. 18.

6 Ibidem, pág. 19.

7 Ibidem, pág. 44. En el año 2000 Emma Pérez Rocha incluyó la carta-petición de Juan Cano a Carlos V en su libro La Nobleza indígena del Centro de México después de la Conquista, en el que presenta una recopilación de documentos escritos por la nobleza nahua en tiempo colonial, elaborada junto con Rafael Tena (Pérez Rocha, Emma, y Tena, Rafael: La Nobleza indígena del Centro de México después de la conquista, INAH, México, 2000, págs. 151-152). 
Cabe señalar que, a pesar de su título, los actores principales del pleito, que escribían peticiones, componían interrogatorios y presentaban testigos, eran Juan Cano, el último de los seis esposos que doña Isabel tuvo a lo largo de su vida, y Juan de Andrade Moctezuma. La intervención directa de doña Isabel en el litigio no fue posible, debido a las normas legales que prohibían a las mujeres casadas presentar sus casos personalmente, así como a su analfabetismo. ${ }^{8}$ Sin embargo, creemos que estas limitaciones no pudieron impedir su participación activa en la larga lucha por comprobar su posición de "única legítima y universal heredera" de Motecuhzoma Xocoyotzin y los correspondientes privilegios. Esta lucha empezó años antes -en 1532 - cuando los frailes franciscanos, por encargo de Juan Cano y de doña Isabel, escribieron dos relaciones. La primera se titula "Relación de la Genealogía y Linaje de los Señores que Han Señoreado Esta Tierra de Nueva España" y la segunda es generalmente conocida como el "Origen de los Mexicanos". ${ }^{9}$ Dirigidos directamente a la corte, ambos documentos ponían de manifiesto los derechos de doña Isabel a todos los bienes de sus antepasados, "señores naturales" de México, asimismo elogiaban sus cualidades personales como "muy buena cristiana" e incluían listados de pueblos y tierras que sus padres habían tenido. ${ }^{10}$ En opinión de Pérez Rocha, estas relaciones tenían carácter preparatorio, con el fin de fundamentar los derechos de doña Isabel a todo el patrimonio de sus antepasados y posteriormente presentar la petición formal de esos derechos, petición que fue realizada catorce años después en la "Información".

Para los esposos Cano estos años pasaron en continua lucha con sus vecinos y con los funcionarios de la Real Audiencia que presentaban reclamaciones contra sus propiedades. Ya en 22 de junio de 1531 el presidente de la segunda Audiencia Sebastián Ramírez de Fuenleal escribió al rey Carlos I que, según su parecer, "Tacuba también con sus sujetos que al presente tiene y sirve doña Isabel, hija de Moctezuma" debía pertenecer a la ciudad de Mexico, porque sin ellos "esta ciudad no se puede buenamente sustentar". ${ }^{11}$ En 1533 los esposos Cano, a su vez, pusieron demanda al fis-

8 Kellogg, Susan: Law and Ttransformation of the Aztec Culture 1500-1700, Oklahoma University Press, Norman, 1995, pag. 106. Ni siquiera pudo firmar su testamento en 1550 y tuvo que pedir al prior del convento de San Agustín que lo hiciera en su nombre. AGI, Justicia, 181, 209r.

9 Relación de la Genealogía y Linaje de los Señores que Han Señoreado Esta Tierra de Nueva España; Origen de los Mexicanos, García Icazbalceta, Joaquín (ed.), en Nueva Colección de Documentos para la Historia de México, Chávez Hayhoe, México, 1941.

10 Ibidem, págs. 280-281. Origen de los Mexicanos..., pág. 306.

11 López de Meneses, Amada: “Tecuichpochtzin, Hija de Moteczuma (1510-1550)” en Revista de Indias, núm. 9, Madrid, 1948, pág. 481. 
cal reclamando "el pueblo de Ocoyocate con sus sujetos", que de hecho estaba en la donación de tierras otorgada por Hernán Cortés para doña Isabel en 1526 "en dote y arras". ${ }^{12}$ En 1535 surgió nuevo pleito con el fiscal sobre "el pueblo de Cuiacaque con los barrios y estancias que se dicen Cupuelaque y Tepenaxuca" y en 1540 uno más sobre "el pueblo de Ocyacate" ya que, según la opinión del fiscal, los esposos lo tenían sin título, o por lo menos sin confirmación. ${ }^{13}$ Mientras tanto, el ganado de los vecinos dañaba las cosechas de doña Isabel y los molinos que construyeron los mayordomos de Hernán Cortés consumían toda el agua necesaria para el riego de sus campos. ${ }^{14}$

Las relaciones de doña Isabel con sus indios súbditos de Tlacopan tampoco eran amistosas. Por lo menos en 1552, apenas dos años después de su muerte, don Antonio Totoquihuaztli, gobernador de Tlacopan, se quejaba de los abusos de doña Isabel que, según sus palabras, "aunque era de nuestra sangre y de nuestra patria, sin embargo tan ajena se mostró de la humanidad, que en lugar del natural amor con que se aman los hombres de una misma tierra y gente, ejerció la tiranía, y a nosotros, que nacimos de padres nobles y preclaros, nos tuvo por siervos". ${ }^{15}$ Todos estos conflictos debían distraer la atención de los esposos Cano de su objetivo principal, puesto que cada uno de ellos duraba muchos años y la sentencia de los jueces locales era contraria frecuentemente a los intereses de la hija de Moctezuma. También es probable que doña Isabel y su marido decidieran buscar el apoyo de la Corona sólo tras perder la esperanza de recibir cualquier resolución a su favor por parte de las autoridades locales. Por último, el inicio de un litigio de tal tamaño por si mismo demandaba tiempo para elaborar argumentaciones que permitieran eliminar posibles objeciones acerca de los derechos de doña Isabel a los bienes en cuestión, en términos jurídicos castellanos, y encontrar los testigos que pudieran proporcionar testimonios favorables. De hecho la "Información de Doña Isabel de Moctezuma" nos presenta una argumentación muy sofisticada que debía ser resultado no de meses sino de años de lucha por los bienes y privilegios. En cuanto a las tierras, pueblos y edificios pedidos en la "Información", su número impresiona y muestra el nivel de ambición de los esposos Cano. Si

12 Ibidem. Documentos Cortesianos: Primera Sección, Martínez, José Luis (ed.), FCE/UNAM, México, 1994, tomo.1, pág. 380.

13 López de Meneses, Amada: “Tecuichpochtzin, Hija de Moteczuma ...”, pág. 484.

14 AGI, México, 1088, r. 3, fs. 39v-40r.

15 Pérez Rocha, Emma, y Tena, Rafael: La Nobleza Indígena del Centro de México después de la Conquista , pág. 169. 
en el "Origen de los Mexicanos" se trataba de 15 pueblos de Motecuhzoma en la Cuenca de México y áreas vecinas, en la "Información" ese número aumentó hasta 117 lugares con varios terrenos situados dentro de sus términos. ${ }^{16}$ Mientras que en el otro documento - la "Relación de Genealogía" - sólo se declaran 10 pueblos, en el lugar donde estaban situadas las tierras de Ahuitzotl, heredados por su hija (la madre de doña Isabel), la "Información" ya nos presenta 39. ${ }^{17}$ Además, se pedía que fueran devueltos los solares y edificios donde entonces residían el virrey y la Real Audiencia, por estar construidos en el lugar que ocuparon los palacios de Motecuhzoma Xocoyotzin. ${ }^{18}$ Entre los bienes reclamados se encontraban también varios terrenos y estancias alrededor del altepetl de Tollan, en el actual estado de Hidalgo, pertenecientes a don Pedro de Moctezuma (Tlacahuepantzin), hermanastro de doña Isabel, y el pueblo de Ecatepec con sus estancias, que Cortés dio en dote a doña Leonor de Moctezuma, media hermana de doña Isabel..$^{19}$ Llama la atención que estos dos parientes cercanos no se mencionen en ninguna parte de la "Información", como si no hubieran existido.

\section{Los argumentos de petición}

La argumentación, que en su forma más evidente se expresa en primeras peticiones al emperador y al presidente de la Real Audiencia y en el interrogatorio de la "Información", compuesto todo por Juan Cano, con la posible ayuda de su esposa, consiste en las siguientes razones:

1) Motecuhzoma Xocoyotzin fue "señor natural de la ciudad de México y de todas sus provincias" y recibió el poder por legítima sucesión de sus antepasados que gobernaban en México "de tiempo ynmemorial". ${ }^{20}$ Además, al conocer la llegada de los españoles, no les hizo ninguna resis-

16 AGI, Patronato, 245, R. 3, fs. 5v-12v; Origen de los Mexicanos..., págs. 255, 277-278.

17 Ibidem, fs. 12v-15r; Ibidem, págs. 277-278.

18 AGI, Patronato, 245, R. 3, fs. 16r.

19 Ibidem, fs. 8v-9r. Pérez Rocha, Emma, y Tena, Rafael: La Nobleza Indígena..., pág. 139; Documentos Cortesianos, tomo 1, pág. 382.

20 Esa fue una tesis muy debatida durante décadas después de la Conquista En 1553, el conquistador Ruy González, en una carta a Carlos V, para tranquilizar la conciencia real y la propia, declaraba que Motecuhzoma "no era legitimo señor" sino tirano y usurpador ya que "tenía otro hermano mayor a quien convenía el señorear" (Epistolario de la Nueva España 1505-1818, recopilación realizada por Paso y Troncoso, Francisco (1939-1942), Zavala, Silvio y colaboradores (eds.), Antigua Librería Robredo de José Porrúa e Hijos, México, 1940, vol. 7, pág. 33). 
tencia ofreciéndoles, al contrario, su ayuda y luego sumisión voluntaria. Por fin "se convirtió a Nuestra Sancta fe catholica", es decir, cumplió con los términos generales del famoso Requerimiento del licenciado Juan López de Palacios Rubios que hasta 1532 servía de doctrina oficial para la Conquista y, en consecuencia, ni él ni sus descendientes debían ser privados ni de su señorío ni de sus bienes.

2) A pesar de ser "gentiles", los padres de doña Isabel se casaron "legítimamente" según las leyes y costumbres de la tierra, delante de muchos testigos y todas las demás mujeres del tlahtoani fueron sus concubinas. Cabe notar que, según la cédula de Carlos I de 1530, las costumbres y leyes indígenas que no contradecían evidentemente a las concepciones castellanas, eran aceptables y, por decisión del Papa Paulo III, los hijos de los señores indígenas nacidos de sus esposas principales antes de la Conquista debían considerarse legítimos y gozar de todos los derechos correspondientes. $^{21}$

3) Los únicos hijos de Motecuhzoma en ese matrimonio eran doña Isabel y su hermano Axayacatl, pero al morir asesinado durante la Conquista este único heredero varón, todos sus derechos pasaron a su hermana doña Isabel. ${ }^{22}$

4) Las tierras y los pueblos solicitados no pertenecían al señorío de México ni a otros pueblos, sino que fueron bienes patrimoniales de Motecuhzoma y su esposa principal. ${ }^{23}$

\section{Los testigos del pleito}

El siguiente paso de importancia consistió en la selección cuidadosa y bien calculada de testigos para la probanza. Los veintinueve testigos de la "Información" eran varones y la palabra masculina, según la legislación de aquella época, valía más que la de las mujeres. ${ }^{24}$ De estos veintinueve,

21 Dougnac Rodríguez, Antonio: Manual de Historia del Derecho Indiano, UNAM, México, 1994, pág. 62. Recopilación de las leyes de los Reinos de las Indias, Cultura Hispánica, Madrid, 1973, 4 vols., vol. 2 , fs. $2-4$.

22 AGI, Patronato, 245, r. 3, f. 8r.

23 Ibidem, fs. 12v-16r.

24 Por ejemplo, cuando Hernán Cortés ya era marqués de Valle fue acusado del asesinato de su primera esposa Catalina Juárez de Marcaida, pero sus procuradores rechazaron la acusación con el pretexto de que "los testigos que en este caso deponen contra el dicho marqués son mujeres y personas de baja condición" (Documentos Cortesianos: Segunda Sección, tomo 2, pág. 206). 
diez $(34,48 \%)$ nacieron entre 1484 y 1490 , por lo que en el tiempo de la Conquista ya eran hombres maduros de unos 31 a 35 años. ${ }^{25}$ Siete testigos (20,60\%) nacidos entre 1492 y 1498 presenciaron la Conquista como jóvenes de entre 21 y 27 años, otros siete $(20,60 \%)$ tendrían en aquel tiempo entre 36 y 41 años. ${ }^{26}$ Sólo tres individuos (10,34\%), nacidos entre 1500 y 1503, serían durante la llegada de Cortés adolescentes o jóvenes de entre 14 y 19 años. ${ }^{27}$ Así, la mayoría de los testigos de la "Información" (89,73\%) eran representantes vivos del tiempo prehispánico, lo que a los ojos de cualquier juez daba más validez a sus declaraciones. En cuanto a la procedencia étnica, parece que todos los testigos de la "Información" eran nahuas, aunque en la documentación de este periodo también aparecen los otomíes, con nombres o títulos nahuas. Casi la mitad de testigos $(44,82 \%)$ eran vecinos de Mexico Tenochtitlan y entre estos últimos predominaban los naturales y vecinos del barrio de San Sebastián, llamado antes de la Conquista Atzacualco: "lugar donde esta el dique". ${ }^{28}$ Solamente tres testigos eran mexicas-tlatelolcas. ${ }^{29}$ Por otro lado, un buen número (13 individuos, el 44,82\%) procedía de otros lugares estrechamente relacionados con Tenochtitlan por ser antes de la Conquista sus tributarios o dependientes. En este grupo tres personas $(10,34 \%)$ eran del pueblo de Ecatepec en la Cuenca de México, otras tres (10,34\%) de Popotla, estancia de Tenochtitlan y siete eran naturales de pueblos de la región de Toluca, tales como Teotenanco Tenanco (Gueytenango en texto), Toluca (Tolucan), Izacualpan, Tepemaxalco, Tlacotepec y Metepec. ${ }^{30}$ Asimismo hay que indicar que cuatro de estos pueblos -Metepec, Tlacotepec, Tolucan y Teotenanco- se mencionan en el Códice Mendocino como conquistas del tlahtoani Axayacatl, padre de Motecuhzoma Xocoyotzin. ${ }^{31}$

En cuanto a la posición social, tres testigos tenían el honorífico don que en tiempo colonial solían gozar los descendientes directos de los señores

25 AGI, Patronato, 181, r. 8, fs. 67v, 71v, 91v, 125v, 139v 98v, 150v y AGI, Patronato, 245, r. 3 , fs. $17 \mathrm{v}, 60 \mathrm{v}, 91 \mathrm{v}$.

26 Ibidem, fs. 74v, 88 r, 95r, 101 v, 107v, 113r, 119 r, 145 v. También ibidem, fs. 47r, 75v, 82r, $103 \mathrm{r}, 111 \mathrm{v}$.

27 AGI, Patronato, 245, r. 3, fs. 33v, 99v, 118r.

28 AGI, Patronato, 181,r. 8, fs. 67v, 71v, 107r, 113r, 125 r-v, 132v, 139r, 145v; AGI, Patronato, 245 , r. 3 , fs. 17 r.

29 AGI, Patronato, 181, r. 8, fs. 74 v, 118v-119r, 150r. $11 \mathrm{r}, 118 \mathrm{r}$.

30 Ibidem, fs. 87v, 92v, 96r, 98r, 101r, 104v; AGI, Patronato, 245, r. 3, fs. 75r, 82r, 99r, 102v,

31 Códice Mendocino o Colección de Mendoza. Echegaray, José Ignacio (ed.). México, San Ángel Ediciones, 1979, fs. 10r-v. 
prehispánicos. De hecho, estos tres eran: el hermanastro de Motecuhzoma Xocoyotzin, don Juan García Achicatzin Huitznahuatl, don Juan de Zacualpa, gobernador de Tzacualpan e hijo de un gobernante precortesiano de este centro toluqueño, y don Miguel Tulnahuacatl. ${ }^{32}$ Trece testigos $(44,82 \%)$ se describen en la "Información" como principales, término que después de la Conquista se usaba como equivalente castellano de la palabra nahuatl pipiltin, "nobles por sangre". ${ }^{33}$ Uno de estos trece nobles, Miguel Huecamecatl, tenía además el título de teuctli (tecuhtli) que en el tiempo prehispánico posiblemente designaba al juez de alto rango, o al jefe de tecalli (linaje noble) en la región de Tlaxcala-Puebla. ${ }^{34}$ Todos los demás se nombran simplemente como vecinos o naturales de cierto lugar. Sin embargo, por los datos que nos proporciona la "Información" parece que tampoco eran plebeyos macehualtin. Diecisiete testigos $(58,62 \%)$ presenciaron las bodas de Motecuhzoma y Tecalco, un evento apenas accesible para la gente común. ${ }^{35}$ Otro quince $(51,72 \%)$ participaron de una u otra manera en las negociaciones de Motecuhzoma con Cortés, unos sirviendo de embajadores al caudillo español y otros presenciando las consultas secretas del tlahtoani con sus nobles ${ }^{36}$ Dieciocho testigos $(62,06 \%)$ acompañaban a Motecuhzoma en su primer encuentro con Cortés en noviembre de 1519. ${ }^{37}$ Lo que más llama la atención con respecto a la posición social de casi todos los testigos de la

32 AGI, Patronato, 181, r. 8, fs. 98r, 118v-119r; AGI, Patronato, 245, r. 3, f. 99r. El nombre nahuatl de este testigo es más bien un título honorífico que daban al guerrero que, sin ayuda de otros, consiguió hacer 4 prisioneros y gozaba de prerrogativas propias de los capitanes. Florentine Codex: General History of Things of New Spain 1950-1982, Anderson, Arthur, y Dibble, Charles (ed., intr. and transl.), University Press of UTAH, 1953, lib. 8, pág. 77.

33 AGI, Patronato, 181, r. 8, fs. 74v, 95r, 98; AGI, Patronato, 245, r. 3, fs. 33r, 46r, 75r, 82r, 102r, 11r, 118r. Lockhart, James: The Nahuas after the Conquest: a social and cultural history of the Indians of Central Mexico 16th through 18th centuries, Stanford University Press, Stanford, 1992, pág. 152.

34 AGI, Patronato, 181, r. 8, f. 150r. Carrasco, Pedro: "Documentos sobre el Rango de Tecuhtli entre los Nahuas Tramontanos", en Tlalocan, México, 1966, n. 5 (2), pág. 145; Rounds, James: "The Role of the Tecuhtli in Ancient Aztec Society”, en Etnohistory, Los Angeles, 1977, págs. 358-360. Chance, John: "Descendencia y Casa Noble Nahua. La experiencia de Santiago Tecali de finales del siglo XVI a 1821”, en Gobierno y Economía en los Pueblos Indios del México Colonial, González Hermosillo Adams, Francisco (coord.). Colección Científica Serie Antropología Social, INAH, Mexico, 2001, pag. 29. Cabe señalar que Miguel Huecamecatl también fue testigo en la "Información sobre los Tributos que los Indios pagaban a Moctezuma" de 1554 y en la "Probanza a favor de don Antonio Cortés Totoquihuaztli y del pueblo de Tlacopan", de 1565-1566. En la última tiene el honorífico de "don".

35 AGI, Patronato, 181 r. 8, fs. 68r, 71v, 74r, 79v, 107v, 113 r, 119r, 125v, 132v, 139v, 150v: AGI, Patronato, 245, r. 3, fs. 18r, 47r, 83r, 92r, 118r.

36 Ibidem, fs. 71r, 78v, 112v, 118v, 124v, 132r, 138v, 145r, 150r, 153r; Ibidem, fs. 32r, 45r, 59r, $73 \mathrm{v}, 98 \mathrm{v}, 110 \mathrm{r}, 122 \mathrm{v}$.

37 Ibidem, fs. $71 \mathrm{r}, 78 \mathrm{v}, 97 \mathrm{v}, 112 \mathrm{v}, 118 \mathrm{v}, 124 \mathrm{v}, 132 \mathrm{r}, 138 \mathrm{v}, 145 \mathrm{r}, 150 \mathrm{r}, 153 \mathrm{r}$; Ibidem, fs. 32r, 45r, 59r, 73v, 98v, 110r, $122 \mathrm{v}$. 
"Información" es la estrecha relación de la mayoría de ellos con la familia de los señores de Tenochtitlan: 16 de ellos $(55,4 \%)$ servían a Motecuhzoma Xocoyotzin o a su predecesor Ahuitzotl, o bien a sus hijos, viviendo en sus casas. ${ }^{38}$ Cuatro de estos $(13,7 \%)$, además, estaban relacionados de un modo u otro con la vida económica de la casa señorial y del estado mexica en general. El testigo llamado Miguel Tescaguacatl (Tezcacoacatl) fue criado de petlalcalcatl, mayordomo principal de Tenochtitlan. ${ }^{39}$ Otro testigo, Martín Mexicatl, fue calpixqui, es decir mayordomo y recolector de tributos de Ecatepec..$^{40}$ Dos testigos, Antón (falta su apellido o más bien el título nahuatl en el texto) y Antonio Huitzpopocatl (Huyzpopocatle en el texto), eran respectivamente hijo y sobrino de los calpixque de Tenayocan y Cuauhtitlan. ${ }^{41}$ Entre el resto de los 25 testigos, 3 servían de pintores o, más concretamente, de escribas (teniendo en cuenta que los españoles siempre se referían a la escritura nahuatl como "pinturas" y la palabra nahuatl tlacuilo se traduce tanto por "escribano" como por "pintor") ${ }^{42}$ de Ahuitzotl y de Motecuhzoma Xocoyotzin. ${ }^{43}$ De otros dos, Miguel Chimalystepetla y Cristóbal Quauhnochtli, se dice que el primero servía de tapia (guardia) a Motecuhzoma y el segundo hacía candela en la casa de Motecuhzoma, a pesar de que, según el cronista Francisco Cérvantes de Salazar, su nombre nahuatl designaba al guerrero que hizo siete cautivos. ${ }^{44}$ En cuanto a los restantes 6 testigos del valle de Toluca sin contar a don Juan de Tzacualpan, uno de ellos - llamado Pedro Ixquen - fue nahuatlato, es decir intérprete de nahuatl del cacique de Tolucan; otro era Martín Mexicatetl, quien frecuentemente iba a la casa de Motecuhzoma en México "a traer leña y otras cosas". ${ }^{45}$ Los demás testigos son nombrados "continos y tenedores" de la casa de Motecuhzoma, sin precisar sus cargos o funciones.

La estrategia del litigio parece clara: ¿Quién podría estar mejor informado de los bienes de los señores mexicas que sus propios criados, participantes activos en la vida cotidiana de la casa señorial de Tenochtitlan?

38 Ibidem, fs. 67v, 71v, 74v, 80r, 120v, 118r-1119v, 139r; Ibidem, fs. 17r, 30r, 46r, 60r, 75r, 91r, 99r, 102v, 111r, 118r.

39 AGI, Patronato, 181 r. 8, f. 74v.

40 Ibidem, f. 80r.

41 Ibidem, fs. 113r, 132v, 135v.

42 Simeón, Rémi: Diccionario de la lengua náhuatl o mexicana, Siglo Veintiuno, México, 1999, pág. 581.

43 AGI, Patronato, 181, r. 8, fs. 71v, 139r; AGI, Patronato, 245, r. 3, f. 91r.

44 Ibidem, fs. 67v; Ibidem, f. 75r; Cervantes de Salazar, Francisco: Crónica de la Nueva España, Editorial de Manuel Magallon, Madrid, 1971, cap. 22, pág. 138.

45 AGI, Patronato, 181, r. 8, fs. 91r, 96r. 
Con sus testimonios, Juan Cano y doña Isabel debían de alcanzar sus fines y así fue teóricamente. En 1556 la Real Audiencia reconoció sus derechos sobre los 117 pueblos y terrenos en cuestión, pero no consideró posible devolverlos a sus cinco hijos porque: "muchos de pueblos que pide y heran de su padre, estan en vuestra real Corona y otros repartidos y dados a conquistadores y pobladores antiguos de la tierra [...] y que si agora se les obiese de quitar y remover causaria gran novedad". ${ }^{46}$ Por entonces doña Isabel ya había muerto hacía seis años. ${ }^{47}$

\section{Don Juan García Achicatzin y las tierras}

Sin embargo, hay una incongruencia notable entre las declaraciones de los testigos sirvientes de Motecuhzoma y Ahuitzotl, y los testimonios de don Juan García Achicatzin, el único testigo que era miembro del linaje gobernante mexica tenochca y en consecuencia pariente de doña Isabel sin tener en cuenta a Antón, su "pariente lejano fuera de cuarto grado". ${ }^{48}$ Mientras que los primeros, aunque discrepaban en detalles, estaban de acuerdo en que las tierras reclamadas fueron propiedades particulares de Motecuhzoma y de Ahuitzotl, don Juan García Achicatzin insistía en que la mayoría de las tierras:

[...] estaban como diputadas para los dichos hijos y nietos o otros desçendientes e parientes de los señores pasados; que de estas dichas tierras gozava el dicho Monteçuma [...] e tenia cargo de todas ellas ecepto que no las podia enagenar en otros estraños ni disponer de ellas... e no obo ninguna dibisión ni partiçion en todas las dichas tierras, pueblos e maçegoales[...] e ansí vio que el dicho Monteçuma repartía entre todos ellos, e hazía repartir los frutos e lo que se avía e adquería dello pero no porque todo fuese del dicho Monteçuma, del dicho patrimonio avido. ${ }^{49}$

Como tierras que "heran particularmente tierras del dicho Monteçuma", don Juan Achicatzin menciona solamente un terreno cerca de Xochimilco, llamado Tepeçingo, otro "gran pedaço de tierra" en términos de Atzcapotzalco, cuatro terrenos con casillas en Chalco y "la provinçia de Taxiaco", ganada por Motecuhzoma en la guerra después de ser elegido

46 Pérez Rocha, Emma: Privilegios en Lucha..., pág. 271.

47 López de Meneses, Amada: "Tecuichpochtzin, Hija de Moteczuma ...”, pág. 495. AGN, Vínculos y Mayorazgos, 181, f. 5r.

48 AGI, Patronato, 181, r. 8, f. 113r.

49 Ibidem, fs. 108v-109r. 110v. 
tlahtoani. ${ }^{50}$ Excluyó por completo de los bienes patrimoniales de sus antepasados los pueblos y tierras de la región de Toluca afirmando "que fueron de la ciudad de Mexico" y "del señorio e no patrimonio". ${ }^{51}$

¿Cómo se pueden interpretar las declaraciones de don Juan García Achicatzin, que refutan casi por completo lo que se dice en las peticiones de Juan Cano y en el interrogatorio? La explicación más sencilla es el interés propio de don Juan en estos bienes. Cabe decir que la maestra Pérez Rocha lo relaciona con don Juan Axayaca, mencionado varias veces en tres cartas de don Pablo Nazareo, un noble indígena de Xaltocan (en la Cuenca de México), a Felipe II y a la reina Isabel, de 1561 y $1566 . .^{52}$ Don Pablo Nazareo se refiere a don Juan Axayaca como a su suegro e hijo del tlahtoani Axayacatl y de Yacuetzin, que a su vez era hija de Achicatzin, principal de Tlatelolco. ${ }^{53}$ La hipótesis de Pérez Rocha parece acertada no sólo por la coincidencia de los nombres y por la costumbre general de los nahuas de tomar el nombre de uno de sus abuelos, sino también por la coincidencia de ciertos datos biográficos que nos presentan estos documentos. Por ejemplo, don Juan Achicatzin, de la "Información", por su colaboración con los españoles después de la Noche Triste, tuvo que refugiarse en el campo de Cortés y lo mismo dice don Pablo Nazareo sobre su suegro. ${ }^{54} \mathrm{Si}$ don Juan Achicatzin, de la "Información de doña Isabel de Moctezuma", y don Juan Axayaca, de las cartas de don Pablo Nazareo, son, en efecto, la misma persona, su conducta durante el pleito de su sobrina se hace más clara. Las cartas de don Pablo Nazareo son patéticas en cuanto a la descripción de la miseria de su familia, incluyendo a su suegro, que por toda su colaboración con los conquistadores no recibió nada. ${ }^{55}$ En ambas cartas aparece un listado de los pueblos "para servicio personal" del tlahtoani Axayacatl (Xiquipilco, Ocuillan, Ocelotepec, Metepec, Xochiyacan, Tzinacatepec) que don Pablo Nazareo pide que se devuelvan a su suegro, don Juan Axayaca, por ser bien-

50 AGI, Patronato, 181, r. 8, fs. 110r, 110v, 111r, 111v.

51 Ibidem, f. 110v. Además, en el "Memorial de los Pueblos de Tlacopan" escrito hacia 1562 los pueblos de Xilotzinco, Ocelotepec, Xochiacan, Tepexic e Itzquitlalpilco que, según la "Información" formaron parte del patrimonio de Motecuhzoma Xocoyotzin, se declaran ser tributarios y dependientes de Tlacopan, el pasado aliado de Tenochtitlan en la Triple Alianza. Pérez Rocha, E., y Tena, R: La Nobleza indígena..., págs. 200-249.

52 Pérez Rocha, Emma: Privilegios en lucha..., pág. 15; Pérez Rocha, Emma, y Tena, Rafael: La Nobleza indígena..., págs. 227-233, 235-243, 333-367.

53 Pérez Rocha, Emma, y Tena, Rafael: La Nobleza indígena..., pág. 353.

54 AGI, Patronato, 181 r. 8, f. 108r; Pérez Rocha, Emma, y Tena, Rafael: La Nobleza indígena..., pág. 343.

55 Pérez Rocha, Emma, y Tena, Rafael: La Nobleza indígena..., pág. 344. 
es de su patrimonio, y estos mismos lugares se mencionan en el listado de pueblos reclamados por Juan Cano y doña Isabel. ${ }^{56} \mathrm{Al}$ parecer los intereses de la segunda estaban en pleno conflicto con los de su tío. Don Juan también quería recibir su parte de bienes e hizo todo lo posible para conseguir tal fin.

\section{Tipología de tierras en las fuentes coloniales}

Sin embargo, si tenemos en cuenta los datos de otras fuentes de la época colonial temprana sobre la tenencia de tierras y el sistema de servicios entre los nahuas antes de la Conquista, creemos que no sería correcto pensar que don Juan Achicatzin, fuera cual fuera su motivo, mentía con respecto a todo mientras que otros testigos decían la verdad. En la mayoría de las fuentes se dice que, en general, antes de la Conquista existieron cuatro categorías generales de tierras:

- Calpullalli (literalmente "tierras de la casa grande"): tierras de comunidades repartidas entre sus miembros para su cultivo. Estaban en posesión común, sin poder ser enajenadas. En los documentos novohispanos escritos en castellano solían llamarse baldios o tierras de barrios. ${ }^{57}$ Con los calpullalli se identifican a menudo los altepetlalli, es decir "tierras de los pueblos", y parece que en estos casos se trata de una misma categoría, ya que la palabra calpulli también se aplicaba al pueblo entero, como por ejemplo en el caso de Molotla, actual Estado de Morelos. ${ }^{58}$

- Tlatocatlalli o tlatocamilli (es decir "tierras de tlahtoani" o "sementeras de tlahtoani"): tierras del gobernante, que él recibía como "sueldo natural" por desempeñar sus funciones de administrador, juez y jefe militar. Tampoco se enajenaban y pasaban junto con el cargo de tlahto-

56 AGI, Patronato, 245, r. 3, fs. 11v-12r; Pérez Rocha, Emma, y Tena, Rafael: La Nobleza Indígena..., págs. 349, 362-363.

57 "Parecer de fray Domingo de Anunciación Sobre el Modo que Tenían de Tributar los Indios en Tiempo de Su Gentilidad", en Epistolario de la Nueva España, vol. 7, pág. 262; "Carta al Rey del Doctor Vasco de Puga, Oidor de la Audiencia de Mexico sobre las Tasaciones de tributes que Hizo en Algunos Pueblos" en Epistolario de la Nueva España, v. 10, pág. 33; AGI, Patronato, 20, r. 22:5, f., 266; Zorita, Alonso: Breve y Sumaria Relación sobre Señores de Nueva España, García Icazbalceta , Joaquín (ed.): Nueva Colección de Documentos para la Historia de México, Chávez Hayhoe, México, 1941, págs. 76-77, 199. Alva Ixtlilxochitl, Fernando: Obras Históricas, edición, introducción y notas de Alfredo Chavero, Oficina Tipográfica de la Secretaría de Fomento, México, 1891-1892, vol. 2, cap. 35, pág. 170. AGI, Patronato, 20, r. 22, f. 266r.

58 Carrasco, Pedro: "La Casa y Hacienda de un Señor Tlalhuica”, pág. 224. 
ani.En la documentación castellana de la época se llaman tierras de señorío. ${ }^{59}$

- Tecpantlalli ("tierras de palacio" o tierras de recámaras de los reyes en terminología castellana): tierras reservadas para mantener la residencia del tlahtoani. Quienes vivían en ellas (tecpanpouhque) estaban obligados a hacer varios servicios en la casa del tlahtoani, tales como traer agua y leña diariamente, liampiar las habitaciones y preparar la comida para los habitantes de palacio. Su posición era hereditaria y tampoco podían enajenar de ningún modo las tierras en las que estaban viviendo. Al morir uno de los tecpanpouhque sin dejar hijos, su tierra era devuelta al tlahtoani, quien la daba a otra persona de la misma categoría. ${ }^{60}$

- Pillalli ("tierras de nobleza"): tierras repartidas entre los nobles hereditarios, parientes cercanos del tlahtoani o descendientes de los tlahtoque y también de los cuauhpiltinli o guerreros de origen plebeyo distinguidos en las guerras. Es la categoría que los españoles llamaban tierras de patrimonio. Loa testigos de la "Información" probablemente usaban el término pillalli con más frecuencia que otros para describir las tierras de Motecuhzoma y Ahuizotl, ya que su equivalente español aparece en la probanza de la "Información", o sea, en la parte que incluye el interrogatorio y las respuestas de los testigos, 325 veces. Muchos de los investigadores que trabajan el problema de la tenencia de tierras las consideraban propiedades privadas de la nobleza nahuatl, aunque esta noción no tiene bastantes argumentos a su favor, como veremos más adelante. ${ }^{61}$

59 Cline, Sarah: The Book of Tributes: Early Sixteenth-Century Nahuatl Censuses from Morelos, en: Nahuatl Studies Series 4, UCLA, Latin American Studies, University Press, Stanford, 1993, pág. 70; AGI, Patronato, 20, r. 22:5, f. 266; Alva Ixtlilxochitl, Fernando: Obras Históricas....2 vols, vol. 2, cáp. 35, págs. 168-169. Relación del Señorío de Teotihuacan en Náhuatl y Español en Pérez Rocha, E., y Tena, R.: La Nobleza indígena..., págs. 386-387. En la última fuente esta categoría de tierras también se llama itonal itlacatl, es decir "la suerte de señor".

60 Alva Ixtlilxochtil, Fernando: Obras Históricas..., vol. 2, cap. 35, págs. 170-171; Torquemada, Juan de: Primera Parte de Veinte y un Libros Rituales y Monarquía Indiana, Oficina de Nicolás Rodríguez Franco, Madrid, 3 vols, vol. 2, Lib. 14, cap. 7, pág. 541.

61 Alva Ixtlilxochitl, Fernando: Obras Históricas..., vol. 2, págs. 168-171; Epistolario de la Nueva España ..., vol. 10, pág. 33; Torquemada, Juan de: Primera Parte de..., vol. 2, lib. 14, cap. 7, pág. 541; Zorita, Alonso: Breve y Sumaria Relación, págs. 76-77, 199. La interpretación de pillalli como las propiedades particulares de los nobles nahuas se encuentra en Gibson, Charles: Aztecs under Spanish Rule. A History of the Indians of the Valley of Mexico 1519-1810, Stanford University Press, Stanford, 1964, pág. 269, Prem, Hanns J: Milpa y Hacienda: Tenencia de la Tierra Indígena y Española en la Cuenca del Alto Atoyac, Puebla, Mexico (1520-1650), INAH, Puebla, 1988, pag. 51; Cline, Sarah: The Book of Tributes: Early Sixteenth-Century Nahuatl Censuses..., pag. 70; Kellogg, Susan: Law and Transformation..., pag. 315 . 
En algunas fuentes también se mencionan las yaotlalli (es decir, "tierras de guerra") situadas en las zonas fronterizas, que parece que nunca se usaban para cultivo y servían como espacios para combates; y las teotlalli ("tierras divinas") o tierras de templos destinadas "para servicio de sus ídolos". ${ }^{62}$

Se puede concluir, a partir de las crónicas y los documentos coloniales que, antes de la Conquista, los tlahtoani desempeñaban el papel de distribuidor principal de las tierras de su dominio. Por ejemplo, Ixtlilxochitl describe como el tlahtoani Nezahualcoyotl de Tezcoco, tras recuperar su dominio en la guerra con Azacapotzalco, dividió todas las tierras en las categorías ya mencionadas, reservando una buena parte para el sustento de sus numerosos parientes. ${ }^{63}$ Tenemos información similar al respecto en Tlaxcala, donde, en tiempos de migración de las tribus chichimecas, los jefes de cierta tribu o de su división repartieron entre sus miembros el territorio recién ganado, que con el tiempo se transformó en altepetl. ${ }^{64}$ Según Chimalpain, la misma práctica era común entre los chalcas antes de la llegada de los mexicas. ${ }^{65}$ Más tarde, en el siglo XV, cuando su territorio fue conquistado por Motecuhzoma Ilhuicamina, el derecho de repartir tierras y establecer sus términos pasó a los gobernantes mexicas, quienes lo aprovecharon para hacer donaciones a sus hijos y hermanos. ${ }^{66}$

Es más que probable que las distintas categorías de las tierras mencionadas en las fuentes coloniales, incluyendo pillalli, tuvieran su origen en el repartimiento inicial llevado a cabo entre los conquistadores mexicas después de su victoria sobre los tepanecos de Azcapotzalco y sus aliados en la Cuenca de México a mediados del siglo XV. ${ }^{67}$ En la Crónica Mexicana de Alvarado Tezozomoc, se describe el repartimiento de tierras del altepetl

62 Epistolario de la Nueva España, vol. 10, pág. 33; Torquemada, Juan de: Primera Parte de..., vol. 2, lib. 14, cap. 7, pág. 541; Reyes García, Luís: Documentos sobre tierras y señorío de Cuauhtinchan, INAH, México, 1978, pág. 106.

63 Alva Ixtlilxochitl, Fernando: Obras históricas..., vol. 2, cap. 35, págs. 168-169.

64 Muñoz Camargo, Diego: Historia de Tlaxcala, Editorial Innovación, México, 1982, págs. 103-104; Carrasco, Pedro: “Documentos sobre el...", págs. 140-141; Zorita, Alonso de: Breve y sumaria..., págs. $76-77$.

65 Chimalpahin, Domingo Francisco: Diario. Las Ocho Relaciones y el Memorial de Colhuacan, Paleografía y traducción al español de Rafael Tena, CONACULTA, México, 2003, vol. 1, págs. 110-112. 255, 277-278.

66 Chimalpahin, D.F.: Diario. Las Ocho ..., vol. 2, pág. 145; Origen de los mexicanos ..., págs.

67 Códice Cozcatzin, estudio y paleografía de Ana Rita Valero de García Lascurain, paleografía y traducción de los textos nahuas de Rafael Tena, INAH / Benemérita Universidad de Puebla, México, 1994, fs. 1r, 9v y 10r. 
como un hecho inmediatamente posterior a su conquista de los altepetl que se ubicaban en esta zona y en áreas vecinas. ${ }^{68}$ Sin embargo, los mexicas, al igual que otros habitantes indígenas del Altiplano, no estaban tan interesados en las tierras mismas como en los servicios que sus habitantes se obligaban a prestar a partir de este momento. Como regla, los mexicas no expulsaban a los vencidos de su territorio, sino que seleccionaban de allí las parcelas más atractivas, que sus habitantes tenían que cultivar para ellos. Asimismo, los vencidos estaban obligados a pagar tributos de los productos artesanales fabricados en sus casas (por ejemplo, los tejidos y recipientes de barro). ${ }^{69}$ Las mayores y mejores parcelas siempre se daban al tlahtoani y a sus parientes cercanos. Según la ya citada Crónica Mexicana, este patrón se aplicaba a todos los centros vecinos, tanto en la Cuenca de México, como en las regiones más cercanas de los valles de Toluca y Matlatcinca. Según esta fuente, los centros donde se llevó a cabo este repartimiento fueron: Coyoacan, Xochimilco, Azcapotzalco, Chalco, Cuitlahuac y Mizquic, en la Cuenca de México, y Metepec, Tolucan y Teotenanco, en el actual Estado de México. ${ }^{70}$ Es preciso señalar que son los mismos centros descritos en el Códice Mendocino, como las conquistas de gobernantes mexicas desde Acamapichtli hasta Axayacatl. Igualmente sus nombres aparecen en la "Información", en el listado de los bienes supuestamente patrimoniales de Motecuzoma y Ahuitzotl. ${ }^{11}$

No obstante, es necesario subrayar que no hay nada en el carácter de estos repartimientos que permita considerarlos como base para fomentar "propiedades privadas" de la nobleza en el sentido común del término. Dice Juan de Torquemada que los nobles que recibían en repartimiento tierras de tlahtoani no podían ni venderlas, ni cambiarlas, ni enajenar de ningún otro modo. De hecho, tenían sólo derecho a recibir sus cosechas y gozar de los servicios personales prestados por sus vecinos. Si tal "poseedor" moría sin herederos o cometía algún crimen grave, las tierras se devolvían enseguida al tlahtoani. En este caso, el cronista habla directamente de

68 Alvarado Tezozomoc, Fernando: Crónica Mexicana escrita hacia el año 1598, notas de Manuel Orozco y Berra, Editorial Leyenda, México, 1944, cap. 15, pág. 57, cap. 18, pág. 68, cap. 20, pág. 77 y cap. 26 , pág. 99.

69 Información sobre los Tributos que los indios pagaban a Moctezuma Año 1554, Scholes, France V., y Adams, Eleanor (eds.), Editorial Porrúa e Hijos, México, 1957, págs. 29-30, 35-36.

70 Alvarado Tezozomoc, Fernando: Crónica Mexicana ..., cap. 18, pág. 68, cap. 20, pág. 77 y cap. 26 , pág. 99 .

71 Códice Mendocino (1979), fs. 2v-9v; AGI, Patronato, 181, R. 8, fs. 63.67r y AGI, Patronato, 245 , R. 3, fs. 6v-16v. 
pillalli y usa este término. ${ }^{72}$ A este respecto es notable también que las "propiedades" de Motecuhzoma Xocoyotzin estuvieran muy a menudo junto con los "patrimonios" de Ahuitzotl. Por ejemplo, la "Información" dice que ambos tenían ciertos barrios en Cuitlahuac y Mixquic, los pueblos situados en la orilla suroccidental de la laguna de Tezcoco, lo que puede ser una prueba indirecta a favor de que en realidad ellos no pertenecían a personas particulares, sino a cierta unidad social, o sea al linaje. ${ }^{73}$

Otros modos que en teoría podrían contribuir a la formación de las grandes propiedades privadas entre la nobleza nahuatl son las donaciones y las dotes. En cuanto a las primeras, uno de los testigos de la "Información" declaró que los gobernantes de Tezcoco habían donado a Motecuhzoma Xocoyotzin una huerta con árboles frutales. ${ }^{74}$ Pero por los datos proporcionados en la "Información" sobre los tamaños de esas donaciones y por la escasez de menciones de tales casos en su texto, resulta imposible que las donaciones pudieran contribuir lo suficiente para formar el enorme patrimonio de 117 pueblos y terrenos que se describen en la "Información". A primera vista las tierras dotales parecen una alternativa más viable. En la "Información", las referencias a las tierras de ese tipo de Tecalco, esposa de Motecuhzoma Xocoyotzin e hija de su predecesor Ahuitzotl, forman el contenido de 13 del total de 39 preguntas del interrogatorio. ${ }^{75}$ También se afirma que todos estos bienes llegaron al poder de Motecuhzoma después de su casamiento con Tecalco. Sin embargo, este dato no se enlaza con los que nos indican otras fuentes y puede ser resultado del fraude deliberado de Juan Cano basado en la práctica jurídica española. En la Historia de Indias de la Nueva España e islas de Tierra Firme de fray Diego Durán y en el Códice Ramírez se dice, en efecto, que durante las bodas los padres de los novios "ponían por memoria todo lo que él y ella traían de provisión de casa, tierras, joyas y atavíos". ${ }^{76}$ Pero enseguida se añade que lo hacían porque: "si acaso se viniesen a descasar (como era costumbre entre ellos en no llevándose bien) hacían partición de los bienes conforme a lo que cada uno trajo". ${ }^{77}$ Así, resulta que, en caso de

72 Torquemada, Juan de: Primera Parte de..., vol. 2, págs. 541-542.

73 AGI, Patronato, 245, r. 3, fs. 11r-11v; 13r.

74 Ibidem, r. 8, f. 82r.

75 Peréz Rocha, Emma: Privilegios en lucha..., págs. 58-60.

76 Durán, Diego: Historia de las Indias de Nueva España e Islas de Tierra Firme, Imprenta de Ignacio Escalante, México, 1880, t. 2, cap. 83, pág. 115; Códice Ramírez o Relación del Origen de los Indios que habitan esta Nueva España según sus historias, Vázquez Chamorro, Germán (ed.), Dastin Historia, Madrid, 2001, pág. 177.

77 Códice Ramírez..., pág. 177. 
divorcio, las tierras dotales se devolvían a la esposa divorciada y en consecuencia las dotes tampoco podían servir de base firme para la formación de una gran hacienda. Aunque las costumbres matrimoniales prehispánicas contaban con un medio como el levirato (casamiento de viuda con hermano de su esposo difunto) para proteger la integridad de la hacienda, esto podía funcionar sólo en caso de viudez..$^{78}$ En la "Séptima Relación", de Francisco Domingo Chimalpahin, se describe con bastantes detalles el casamiento de una hija de Motecuhzoma Xocoyotzin con el tlahtoani Necuametzin de Tzaqualtitlan Tenanco (en la región de Chalco) y en este caso no se trata de tierras dotales, sino de la de gente del servicio. "La señora llevó consigo dos tlaxilacatin (comunidades) de otomíes para que la sirvieran en Tlalmanalco; se los envió Motecuhzomatzin porque esos otomíes eran desde antes sus macehuales" —explica el cronista. ${ }^{79}$

Si ni las donaciones ni las dotes podían servir para el fomento de las grandes propiedades prehispánicas -cosa que nos intenta exponer la "Información"- queda sólo una opción que consiste en la compra de tierras. Aquí se debe regresar a una cuestión muy debatida desde los tiempos coloniales. La pregunta es si la tierra en la sociedad nahuatl prehispánica se consideraba una mercancía. Creemos que los datos actualmente disponibles están más a favor de una respuesta negativa a esta pregunta. Por un lado, el mismo don Juan Achicatzin repite en dos ocasiones que su hermano Motecuhzoma Xocoyotzin "compró con sus propios dineros" un terreno cerca de Xochimilco. ${ }^{80}$ Como se puede deducir, la frase entera tal y como está escrita ahora es el resultado de diversas transformaciones que sufrían las declaraciones de los testigos presentados en nahuatl. Al traducirlas al castellano y ponerlas por escrito los escribanos, quienes por lo visto no conocían esa lengua, se producían modificaciones, que se volvían a repetir en el momento en el que las declaraciones eran copiadas por otros escribanos que tampoco eran expertos en nahuatl. La palabra "dineros", introducida en la respuesta de don Juan por el intérprete o escribano, es, sin lugar a dudas, una de las tantas imposiciones castellanas de la "Información" gracias al origen híbrido del testimonio elaborado en pleno acuerdo con el procedimiento judicial castellano, pero basado en declaraciones indígenas. Cabe decir que otro testigo, Miguel Huecamecatl, pre-

78 Historia de los Mexicanos por sus Pinturas, Orozco y Berra, Manuel (ed), en Anales del Museo Nacional de México, México, 1882, pág. 106.

79 Chimalpahin, Domingo Francisco : Diario. Las ocho..., vol. 2, pág. 145.

80 AGI, Patronato, 181, r. 8, f. 110r. 
guntado en 1554 por la misma Real Audiencia sobre el valor de tributos pagados a Motecuhzoma en dinero, dijo que no sabía decirlo porque: "como dicho tiene no había dinero" ${ }^{81}$ La palabra más común para "dinero", tomín, aparece en los textos escritos en nahuatl hacia $1545 .^{82}$ Aun en las primeras décadas después de la Conquista según fray Toribio de Benavente, apodado Motolinía, las mercancías vendidas en las plazas especiales "todas son moneda y unas truecan por otras". ${ }^{83}$

Existen otros testimonios sobre la compra y venta de tierra, aunque su carácter es igualmente cuestionable. En un catastro de los bienes de uno de los hijos del último gobernante prehispánico de Texcoco (Nezahualpilli), don Carlos Ometochtli Chichiomecatecuhtli, que acabó su vida en la hoguera de la Inquisición, conocido como el Mapa de Oztoticpac y supuestamente fechado hacia 1540, se mencionan cuatro terrenos que el malogrado don Carlos compró a cambio de mantas sencillas y de labores. ${ }^{84}$ Sin embargo, esta transacción tuvo lugar casi dos décadas después de la Conquista y fue realizada por un representante de la nobleza indígena criado en la casa de Cortés, educado por religiosos franciscanos y, en consecuencia, ya bien aculturado. ${ }^{85}$ También llama la atención el pequeño tamaño de estas parcelas y lo insignificantes que resultan en comparación con las tierras que don Carlos poseía junto con otros miembros del linaje de los gobernantes de Texcoco. ${ }^{86}$ Juan de Torquemada afirma que los cuauhpipiltin, guerreros que alcanzaron la posición de nobles por sus hazañas militares y recibieron tierras: "no podían tener terrazguerros, y podían vender a otros principales, como no fuese cosa, que el señor huviese hecho condicionalmente; y a ningún macehual (que es villano) los unos ni los otros no podían venderselas". ${ }^{87}$ También tenemos el "Parecer de fray Domingo de la Anunciación sobre el modo de tributar que tenian los indios en el tiempo de la gentilidad" (1554), un informe detallado de un fraile dominico que se

81 Información sobre los Tributos..., pág. 37.

82 Karttunen, F., y Lockhart, J.: Nahuatl in the Middle Years: language contact phenomena in texts of colonial period, University of California Press, Los Angeles, 1976, lib. 14, cap. 7, pág. 54.

83 Motolinia, fray Toribio de Benavente: Memoriales o Libro de las Cosas de la Nueva España y de los Naturales de ella, UNAM, México, 1971, pág. 374.

84 Cline, Howard F.: "The Oztoticpac Lands Map of Texcoco", Quartely Journal of the Library of Congress, vol. 23, n. 2, Washington DC, 1966, pág. 22.

85 Proceso criminal del Santo Oficio de la Inquisición y del fiscal en su nombre contra Don Carlos, indio principal de Tezcoco, Luís González Obregón (ed.), México, 1910, págs. 66-67.

86 Cline, Howard F.: “The Oztoticpac Lands Map...”, págs. 22, 24.

87 Torquemada, Juan de: Primera Parte de ..., vol. 2, lib. 14, cap. 7, pág. 546. 
entrevistó con seis nobles nahuas de Chimalhuacan, el centro principal de Chalco. Allí fray Domingo escribe:

dicen que las tierras que poseían eran del pueblo y del común y de los barrios que tenían repartidos, y algunos principales vendieron parte de estas dichas tierras a personas particulares y aquestos que las compraron las dejaron a sus descendientes, empero que al principio eran tierras de pueblo que ellos llaman altepetllalli o calpullali. ${ }^{88}$

Esta información está en contradicción evidente con los datos de otros documentos, incluyendo la Relación de los señores de la Nueva España del oidor Alonso de Zorita, en la que se postula que vender la tierra de comunidad estaba prohibido.$^{89}$ ¿Acaso en el "Parecer de fray Domingo" se trata de una práctica regional de chalcas? Tampoco se puede descartar por completo la posibilidad de una traducción incorrecta del nahuatl. En cuanto a los términos relacionados con compra y venta de tierras en esa lengua, tenemos sólo dos ejemplos en documentos separados por décadas y procedentes de las diferentes zonas del Altiplano. En otro catastro temprano del actual Estado de Morelos (entre 1532-1540) aparece la palabra ymilcoval ("su sementera comprada"), mientras que en el Códice Florentino, concluido ya en 1579, se encuentra otro término, tlalcohualli ("tierra comprada"). ${ }^{90}$ No podemos estar seguros de su origen prehispánico. La primera palabra "no aparece como fórmula común en otras partes de censo", ${ }^{91}$ en tanto que el Códice Florentino, debido a sus fechas tardías, contiene una buena proporción de palabras que ya reflejan realidades coloniales. Uno de los pocos testimonios detallados sobre la "compra de tierras" antes de la Conquista provoca actualmente dudas muy serias sobre si en efecto se trata de esa acción. Es un documento titulado Verba Sociorum Domini Petri Tlacauepantzi, escrito en latín como parte de la probanza a favor de don Pedro de Moctezuma Tlacahuepantzin, hermanastro de doña Isabel. Allí uno de los testigos, Andrés Tlailotlac, dice que:

El campo llamado Xicococ lo compró el señor Ixtlilcuechaoacatzin [el tlahtoani de Tollan Xicotitlan y el abuelo materno de don Pedro] a los mayores de Tollan; pagó por él 100 plumas preciosas de las que entre nosotros se llaman quetzalli, 140 cargas de

88 Epistolario de la Nueva España, vol 7, pág. 262.

89 Zorita, Alonso de: Breve y sumaria..., pág. 77.

90 Cline, Sarah: The Book of Tributes: Early Sixteenth-Century Nahuatl Censuses from Morelos, en: UCLA, Latin American Studies, University Press, Stanford, 1993, vol. 81, pag. 70; Florentine Codex..., vol. 10, pág. 21.

91 Cline, Sarah: The Book of..., págs. 70-71. 
granos y 120 vestidos, 40 prendas de las llamadas huipilli y otras tantas de las llamadas cueitl. se pagaron asimismo por el campo de Xicococ 60 cargas de semillas llamadas chíen y 40 cargas de legumbres. ${ }^{92}$

Teniendo en cuenta que en la sociedad nahuatl prehispánica la ropa y los alimentos servían como "dinero" para comerciar, este testimonio parece fidedigno, pero otro testigo, Alonso Chichimecateuctli, lo refutó por completo explicando:

Todas estas cosas no las entregó a nuestros mayores como precio para comprar el campo, sino como regalo y obsequio; y todo lo que dio a nuestros mayores éstos no lo recibieron tan de buena gana, ya que lo colocaron en cierto sitio para que allí se pudriera; en cuanto a las plumas preciosas llamadas quetzalli, se las devolvieron a señor Yxcuetzi, hijo de Yxtlilcuechaocatzin, y aquél las usó en sus bailes. ${ }^{93}$

Si eso hubiera sido ciertamente una "transacción" con el campo de Xicococ, esta manera de "usar" el "dinero" pagado resultaría más bien rara. Por lo visto, se trata no de una transacción con tierra en el sentido habitual del término, sino de una solicitud de acceso al campo en cuestión por parte del tlahtoani Ixtlilcuechaoacatzin para aprovecharse de sus cosechas, solicitud que fue rechazada por los mayores de Tollan. Así, este ejemplo muestra que la tierra probablemente no se consideraba como mercancía y venta, sino como un medio de producción que no podía ser enajenado bajo ningún pretexto.

El análisis de términos nahuas para "patrimonio", "hacienda" y "propiedad" que presenta el famoso Vocabulario en Lengua Castellana y Mexicana de fray Alonso de Molina, la recopilación más completa del nahuatl clásico, que contiene muchos vestigios de la época prehispánica, tampoco favorece la idea central de la "Información" acerca de que las tierras y pueblos reclamados por Juan Cano en nombre de doña Isabel habían sido propiedades privadas de Motecuhzoma y Ahuitzotl, tenidas "aparte de señorío", es decir, de los tlatocamilli. Lo más importante es que en la parte nahuatl de ese Diccionario no se hace la distinción léxica entre "patrimonio" y "señorío" que tanto se destaca en la "Información". Ambos conceptos se traducen por la misma palabra: tlatocayotl, curiosamente derivada de tlahtoani (gobernante o señor), al añadir yotl, el sufijo de pluralidad abs-

92 Pérez Rocha, Emma, y Tena, Rafael: La Nobleza indígena..., pág. 142.

93 Ibidem, pág. 147. 
tracta. ${ }^{94}$ La palabra más común en el Vocabulario de Molina -"propiedad"es tlatlaquitl, cuyo significado, "algo para llevar", demuestra que se refiere literalmente a los bienes muebles. De hecho, su segundo significado es "ropa". ${ }^{95}$ Finalmente hay que reparar en la coincidencia casi absoluta del listado de los pueblos y las tierras reclamadas en la "Información" con los de los pueblos tributarios del Códice Mendocino (hacia 1545) y de la Información sobre los Tributos que los Indios Pagaban a Moctezuma (1554). Curiosamente, los 117 pueblos reclamados en la "Información" se mencionan también en estas dos fuentes no como las propiedades de los gobernantes mexicas sino como los tributarios "del señorío de México", es decir, del Estado mexica. ${ }^{96}$

\section{Las reflexiones finales}

Así, resulta muy probable que en los tiempos prehispánicos no hubiera una división estrictamente marcada entre las tlatocamilli y las pillalli, ya que ambas categorías tenían un origen común y posiblemente podían pasar de una categoría a otra, dependiendo de las necesidades del momento. De hecho, la cantidad de pipiltin, a quienes Zorita describe como "hijos y nietos de señores pasados" es impresionante gracias a la poliginia practicada por la nobleza nahua. Sólo el tlahtoani Axayacatl tenía 20 hijos, su hermano Ahuitzotl 18, y su hijo Motecuhzoma Xocoyotzin 19. ${ }^{97}$ A su vez, ellos dejaron sus propios hijos y, como consecuencia, cada tlahtoani prehispánico era representante de un número determinado de parientes, cuyos intereses tenía que apoyar. Dada la ausencia de dinero antes de la Conquista, el único modo de sustentar a todos los parientes consistía en proporcionarles tierras o, más concretamente, obligar a los vecinos de tal o cual barrio a cultivar unas parcelas para uno de los miembros del linaje gobernante mexica, y esto es precisamente lo que decía don Juan Achicatzintzin en el litigio. Esa acción fue llevada a cabo por medio de las conquistas de los centros en la Cuenca de México y en las áreas más cercanas, ya que debido a la ausen-

94 Molina, Fray Alonso de, : Vocabulario en Lengua Castellana y Mexicana, Casa de Antonio Espinosa, México, 1571, f. 40r.

95 Ibidem, f. 42r.

96 Códice Mendocino (1979), fs. 19v-25v; 27v-33v; Información sobre los tributos..., págs. 30, 32-35, 42-44.

97 Alvarado Tezozomoc, Fernando: Crónica Mexicana..., págs. 138-139, 143-146, 150-152. 
cia de animales de carga, este sistema de explotación de las regiones más lejanas no hubiera sido efectivo, y por eso todas las tierras reclamadas por doña Isabel estaban en términos de este territorio. Posteriormente empezaron a formarse diferentes ramas del linaje señorial mexica, cada una de las cuales mantenía el control sobre un determinado territorio que recibió en repartimiento inicial, pero la totalidad de tierras estaba en poder del linaje entero y el carácter corporativo de la tenencia de tierra se conservó hasta la Conquista por medio de la posesión conjunta y de las alianzas matrimoniales dentro del linaje. Es curioso a este respecto notar que en la misma "Información" están mencionados casos de tal posesión conjunta y matrimonios con el fin de conservar las tierras en los límites del linaje. Se dice, por ejemplo, que los hijos de Ahuitzotl - Atlixcatzin y Tecalco- poseían juntos los pueblos de Chichiguatla y Aguatepeque. ${ }^{98}$ Cuando Tecalco se casó con su primo Motecuhzoma Xocoyotzin, ella "llevó consigo" la mitad de estos pueblos, pero ya en la generación siguiente dicha mitad fue devuelta a Atlixcatzin por medio de su matrimonio con Tecuichpochtzin. ${ }^{99}$ De hecho, los datos de la "Información", junto con los de la Crónica Mexicayotl o los de la Información a favor de don Pedro Tlacuepantzin, permiten afirmar que las mismas tierras y pueblos circulaban durante generaciones dentro de una rama particular del amplio linaje gobernante mexica-tenochca. Pero tal patrón hubiera sido posible si toda la hacienda entera hubiese pertenecido a cierta unidad social interesada en asegurar su integridad. Una evidencia explicita a favor del carácter corporativo de la tenencia de tierras antes de la Conquista y aun en el tiempo colonial se encuentra en el ya citado Códice Cozcatzin, fechado por el año 1572. Allí, en la primera sección se presentan las reclamaciones de 55 "familias", a las que hacia el año 1569 don Diego de Austria de Mendoza Motecçuma, gobernador de Tlatelolco, había desposeido de sus tierras patrimoniales "tiránicamente y con poco temor de Dios Nuestro Señor". ${ }^{100}$ Nosotros ponemos el termino "familia" entre comillas, porque de hecho se trata de amplios grupos de parientes, en su mayor parte de hermanos y primos, descendientes de los guerreros del tlahtoani Itzcoatl que antes poseían juntos las tierras reclamadas. De hecho la fórmula que se aplica a terrenos en cuestión es "nuestras

98 AGI, Patronato, 181, r. 8, fs. 71v-72v. .

99 AGI, Patronato, 245, r. 3, f. 19v. Curiosamente la "Información" es la única fuente que menciona este matrimonio de doña Isabel, que tuvo lugar poco antes de la llegada de los españoles

100 Códice Cozcatzin, f. 10r. 
tierras" y en ningún caso "mi tierra" ${ }^{101}$ Además se afirma que este patrón de tenencia colectiva se conservaba desde 1439, cuando Itzcoatl repartió las tierras recién conquistadas entre sus guerreros participantes en la guerra tepaneca, hasta la expropiación realizada por don Diego. ${ }^{102}$

El carácter corporativo de la tenencia de tierra entre la nobleza prehispánica nos explica por qué, según Juan de Torquemada, los pipiltin no podían "vender" la tierra recibida del tlahtoani a gente común. ${ }^{103}$ Los nobles eran miembros de diferentes grupos del mismo linaje, descendientes de los primeros tlahtoque, y como tales podían transferir sus tierras sólo dentro de su linaje. La situación reconstruida tiene mucho en común con el modelo de maison o casa, elaborado por el antropólogo francés Claude Lévi-Strauss. Él define la maison o casa como: una persona moral detentadora de un dominio constituido a la vez por bienes materiales e inmateriales, que se perpetúa por la transmisión de su nombre, de su fortuna y de sus títulos en línea real o ficticia, tenida por legítima con una sola condición: de que esta continuidad pueda explicarse en el lenguaje del parentesco o de la alianza, y la más de las veces de los dos al tiempo. ${ }^{104}$

Los datos extraídos de las investigaciones etnohistóricas demuestran que las casas son unidades sociales que usan el lenguaje de parentesco para establecer sus derechos a ciertos bienes. ${ }^{105} \mathrm{~A}$ diferencia de los clanes, por ejemplo, las casas combinaban lazos tanto de descendencia como de matrimonio para administrar su membresía a través del tiempo, porque su mayor propósito era mantener propiedades tangibles e intangibles a toda costa durante muchas generaciones.

Creemos que precisamente por esa razón otros parientes cercanos de doña Isabel, excepto don Juan Achicatzin, no fueron seleccionados como testigos de la "Información", y este último no volvió a declarar tras presentar un testimonio tan poco favorable a los objetivos de doña Isabel y de

101 Ibidem, fs. 3r-9v.

102 Ibidem,fs. .9v-10r.

103 Torquemada, Juan de: Primera Parte de Veinte..., vol. 2, lib. 14, cap. 7, pág. $5 z 46$.

104 Lévi-Strauss, Claude: La vía de las máscaras, Siglo Veintiuno, México, 1981, pág. 150.

105 Véase por ejemplo Neurath, Johannes: "La maison de Lévi-Strauss y la casa grande wixarika” en Journal de la Société des Américanistes, vol. 86, Paris, 2000, págs. 113-127; Lamas, Marta: "Las reglas de matrimonio entre los mixtecos. El caso de 8 Venado, 'Garra de Tigre', rey de las dos Mixtecas", en Cultura y comunicacion: Edmund Leach in memoriam, Jesús Jáuregui, María Eugenia Olavarría, y Víctor M. Franco Pellotier (eds.), UNAM/ CIESAS, México, págs. 121-127; Gillespie, Susan D.: "Rethinking Ancient Maya Social Organization: Replacing 'Lineage' with 'House." en American Anthropologist, vol. 102, n. 3, 2000, págs. 467-484. 
Juan Cano. Tras la Conquista, cuando el orden anterior sufrió un golpe duro, resultó fácil cometer un fraude deliberado con la ayuda de testigos seleccionados para este fin y presentar los tlatocamilli y tecpantlalli, antes bienes corporativos del linaje gobernante mexica, como propiedades privadas de los antepasados directos de doña Isabel. 